\title{
The effects of emotional value of conclusions upon distortion in syllogistic reasoning
}

\author{
HARRY KAUFMANN ${ }^{1}$ AND STEPHEN GOLDSTEIN
}

UNIVERSITY OF TORONTO

Ss assessed the validity of syllogisms varying in affective loading, quantification, and validity. Syllogisms with existential conclusions resulted in more errors than syllogisms with universal conclusions, and more invalid syllogisms were incorrectly accepted than were valid ones incorrectly rejected. This difference was greatest for existential arguments with positive affect.

Common observation and empirical research indicate that individuals are often at fault in their reasoning. A classical study by Woodworth \& Sells (1935) illustrated an "atmosphere" effect in logical reasoning, in which a "global feeling" or "impression" created by the types of premises used in a syllogism influenced the kinds of conclusions drawn. They also showed difficulty in reasoning caused by ambiguity in the language. (For instance, the word "some" means "at least one and perhaps all" in logical terms, whereas in every day parlance it is more often taken to mean "more than two but not all.") Finally, they report a "caution" or "wariness" effect in which the individual is more likely to accept a particular conclusion than a universal one.

Other research has shown that attitudes affect the reasoning process. Studies by Lefford (1946), Janis \& Frick (1943), and Feather (1964) showed that the distortion of reasoning is greater for syllogisms containing emotional subject matter, or is greater for syllogisms in which the conclusion has previously been accepted.

However, existing studies still contain some ambiguities: (1) Some studies (Janis \& Frick, 1943; Thouless, 1959) did not employ "neutral" statements but only those in winich $\mathrm{S}$ was emotionally involved, and this failed to control for "atmospheric" effects such as those found by Woodworth \& Sells (1935). (2) Some studies (Lefford, 1946; Thistlewaite, 1950; Morgan \& Morton, 1914, did not include negatively affective statements with which Ss are likely to disagree, and thus failed to control for acquiescence. (3) Most pertinent studies failed to consider Woodworth \& Sells' (1935) "caution effects." If present, they would lead to greater errors in existential statements ("some $x$ are $y$ ") than in universal ones ("all $x$ are $\left.y^{\prime \prime}\right)$ if the conclusion is invalid. Conversely, the same wariness would lessen the acceptance of valid conclusions drawn from universal statements. (4) The previous experiments dealing with the effect of attitudes about conclusions on syllogistic reasoning tested S's attitudes towards these conclusions before or after the syllogism test. It is possible that these methods might have led to commitment for the second task. Thus, the opinions expressed could affect the subsequent evaluation of the syllogism, or a conclusion correctly or incorrectly derived from a syllogism might crystallize into an opinion.

The present experiment attempts to control for the possible confounding effects listed above.

The following hypotheses were tested: Hypothes is 1: Syllogisms with both positively affective (PA), and negatively affective (NA) conclusions result in more errors in reasoning than syllogisms with neutral (N) conclusions. Hypothesis 2: Due to the wariness or caution of Ss to draw universal conclusions, more existential than universal errors occur. Hypothesis 3: Since the "twoway" process of distortion involves distortion in the direction of one's opinion, the order of erroneous acceptance of invalid arguments is $\mathrm{PA}>\mathrm{N}>\mathrm{NA}$, while the order of erroneous rejection of valid arguments is $\mathrm{NA}>\mathrm{N}>\mathrm{PA}$.

\section{Affective value and quantification of conclusion.}

Before the experiment, a list of 40 statements was formulated, differing with respect to quantification (Q), so that half were existential (E) and half universal (U). The list was randomized and presented to a group of 112 students enrolled in an introductory psychology course at the University of Toronto. Ss were asked to mark " $A$ " beside those statements with which they agreed, and to mark " $D$ " beside those with which they disagreed. Statements with which over $80 \%$ agreed were then used as "positive affect" (PA) statements and those with which over $80 \%$ disagreed were used as "negative affect" (NA) statements. Twelve PA and twelve NA statements from this list were used as conclusions in the syllogism test. In addition, 12 presumably neutral (N) statements were formulated.

\section{Validity of the syllogism.}

Valid syllogisms (V) conformed to the formal rules of logic, whereas invalid ones (I) contained simple logical fallacies.

Thus there were 36 syllogisms containing a major and a minor premise and a conclusion divided into 12 types depending upon the affective value of the conclusions, the degree of quantification of the conclusions, and the degree of validity of the syllogism. Subjects

Thirty-two female Ss were used. They were all students enrolled in an introductory course in psychology at the University of Toronto, but none of 


\begin{tabular}{|c|c|c|c|c|c|c|c|}
\hline & \multicolumn{2}{|c|}{ PA } & \multicolumn{2}{|c|}{ NA } & \multicolumn{2}{|c|}{$N$} & \\
\hline$U$ & $\begin{array}{r}V \\
.25\end{array}$ & $\begin{array}{l}1 \\
.44\end{array}$ & $\begin{array}{r}V \\
.31\end{array}$ & $\begin{array}{l}1 \\
.25\end{array}$ & $\begin{array}{l}V \\
.22\end{array}$ & $\begin{array}{c}1 \\
1.44\end{array}$ & 2.91 \\
\hline$E$ & .16 & 2.03 & .50 & 1.09 & .94 & 1.23 & 5.95 \\
\hline $\begin{array}{l}\text { Sub Totals } \\
\text { Totals }\end{array}$ & .41 & 2.47 & .81 & 1.34 & $\begin{array}{l}1.16 \\
3.82\end{array}$ & 2.67 & 8.86 \\
\hline
\end{tabular}

them were the same Ss that had previously filled out the attitude questionnaire, and none of them had ever received formal instruction in logic.

\section{Procedure}

Ss were tested in groups of about 10. Each S was given the same syllogism test containing the 36 syllogisms. The syllogisms were randomly presented to avoid order of presentation effects. The instructions clearly stated the logical meaning of universal and existential quantification. Most Ss completed the test within about a half-hour.

\section{Results}

Each of the 32 syllogism tests was scored according to the mean number of errors made. These data are shown in Table 1. Analysis of variance showed all main effects and interactions significant at the .01 level. (The Subjects and Subjects by Validity effects were also significant.)

Directly contrary to Hypothesis 1 , the mean number of errors for syllogisms with $N$ conclusions was greater than that of either PA or NA, though this reversal occurred only for $E$ statements. Hypothesis 2 of higher $E$ than $U$ errors was confirmed, but the effect was due mainly to acceptance of PA-I conclusions. For $E$ type statements, the order of acceptance of I conclusions was $\mathrm{PA}>\mathrm{N}>\mathrm{NA}$, as predicted by Hypothesis 3 , and the rejection of V-PA conclusions was lower than that for NA or $\mathrm{N}$, although the order of the two latter conditions is the reverse of that predicted by Hypothesis 3. Hypothesis 3 was thus confirmed for $\mathrm{E}$ statements.

Discussion

The strong validity and triple interaction effects show that no sweeping statements can be made about errors, affective loading, or quantification by themselves. Errors of acceptance occurred more readily than errors of rejection, and the alleged obfuscation of reasoning due to affective loading seemed to apply only to such acceptance, but not to rejection errors, and there mainly for positively affective universal statements. Caution effects were absent for invalid, neutral statements.

The interaction between the affective value of conclusions and their degree of quantification implies that a syllogism with emotional content may produce greater wariness of accepting a universal conclusion than if the syllogism were without affective content. Neutral statements may reduce interest and lead to acceptance regardless of quantification. It should be noted, however, that this "acquiescence" effect is conditional upon the subject matter and does not differentiate across Ss. This lends support to Rorer's (1965) assertion that no general acquiescence set need be postulated.

\section{References}

Feather, N. J. Acceptance and rejection of arguments in relation to attitude strength, critical ability and intolerance of inconsistency. J. abnorm. soc. Psychol., 1964, 69, 127-136.

Janis, I. L., \& Frick, F. The relationship between attitudes towards conclusions and errors in judging logical validity of syllogisms. J. exp. Psychol., 1943, 33, 73-77.

Lefford, $A$. The influence of emotional subject matter on logical reasoning. J. gen. Psychol., 1946, 34, 127-151.

Morgan, J. J. B., \& Morton, I. F. The distortion of syllogistic reasoning produced by personal conviction. J. soc. Psychol., $1944,20,39-59$.

Rorer, L. G. The great response style myth. Psychol. Bull., 1965. 63, $129-158$.

Thistlewaite, D. L. Attitude and structure as factors in the distortion of reasoning. J. abnorm. soc. Psychol., 1950, 45, 442458.

Thouless, R. M. Effect of prejudice on reasoning. Brit. J. Psychol., 1959, 50, 289-293.

Woodworth, R. S., \& Sells, B. An atmosphere effect in formal syllogistic reasoning. J. exp. Psychol., 1935, 18, 451-460.

\section{Note}

1. The present study was conducted while the Senior Author held Ontario Mental Health Foundation Grant No. 93. 